\title{
ОЦЕНКА ВОЗДЕЙСТВИЯ КОМПОСТА НА ЭКОЛОГИЧЕСКИЕ СВОЙСТВА ЧЕРНОЗЕМА ВЫЩЕЛОЧЕННОГО ПРИ ПЕРЕХОДЕ НА ОРГАНИЧЕСКОЕ ЗЕМЛЕДЕЛИЕ
}

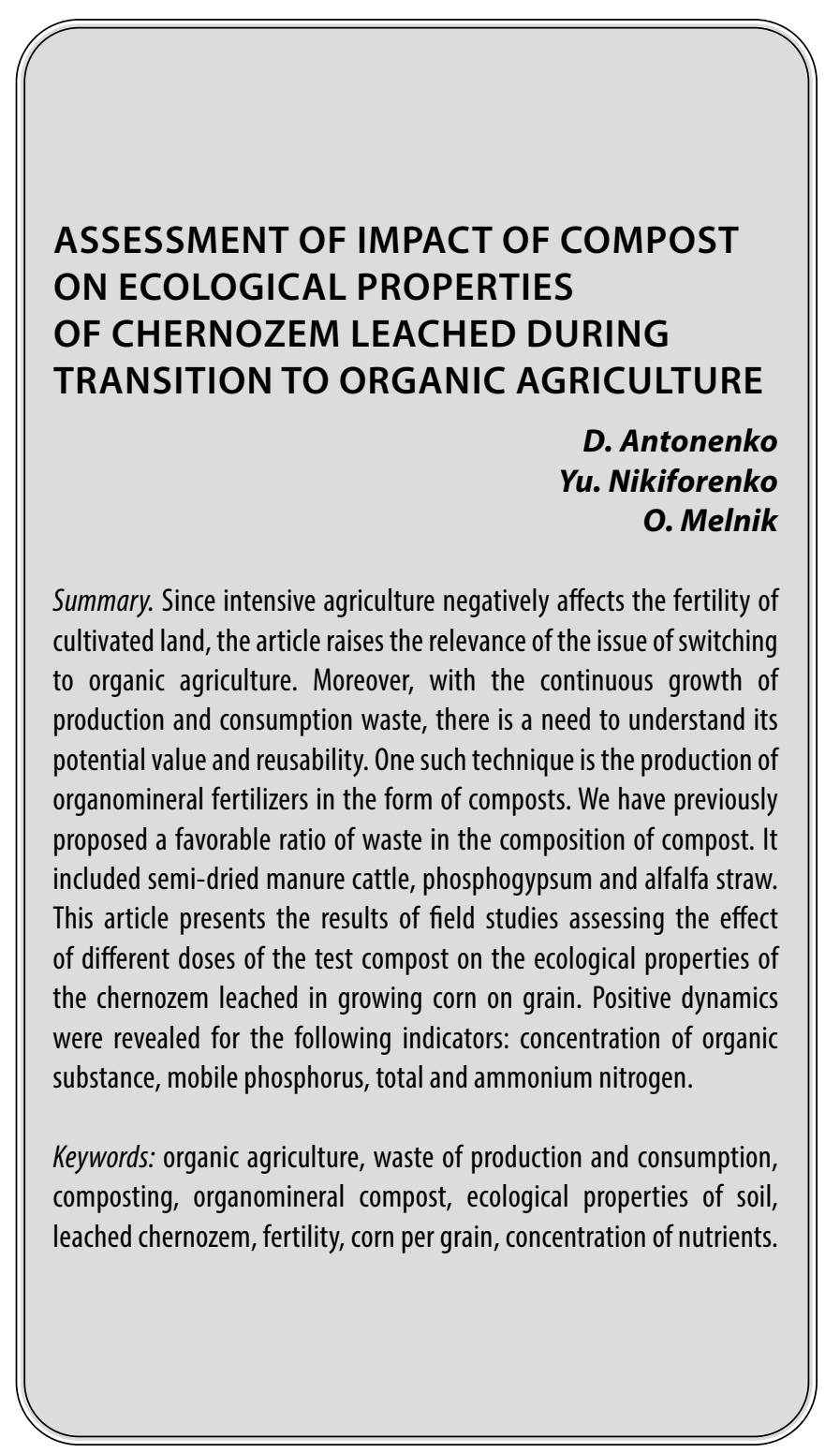

$\mathbf{4}$ еловеческая деятельность ежедневно связана с образованием и накоплением отходов, избавление от которых является проблемой мирового масштаба. Массовое складирование отходов приводит к загрязнению ландшафтов, снижению плодородия почв, потере ими экологических функций и нарушению естественного восстановления экосистем. В результате, идет интенсивное накопление загрязняющих веществ в различных компонентах окружающей природной
Антоненко Дарья Алексеевна

К.с.-х.н., дочент, Кубанский государственный аграрный университет имени И.Т. Трубилина

(2. Краснодар)

dasha-slav@rambler.ru

Никифоренко Юлия Юрьевна

К.б.н., дочент, Кубанский государственный аграрный университет имени И.Т. Трубилина

(2. Краснодар)

petuh_yulya@mail.ru

Мельник Ольга Александровна

К.б.н., дочент, Кубанский государственный аграрный университет имени И.Т. Трубилина

(2. Краснодар)

melnik_olga240781@mail.ru

Аннотация. Поскольку интенсивное сельское хозяйство негативное влияет на плодородие возделываемых земель, в статье поднимается актуальность вопроса перехода на органическое земледелие. К тому же, в условиях непрерывного роста объемов отходов производства и потребления возникает необходимость понимать их потенциальную ценность и возможность вторичного использования. Одним из таких технологических приемов является получение органоминеральных удобрений в виде компостов. Ранее нами предложено благоприятное соотношение отходов В составе компоста. В него вошли полуперепревший навоз КРС, фосфогипс и солома люцерны. В данной статье приводятся результаты полевых исследований по оценке воздействия разных д0з исследуемого компоста на экологические свойства чернозема выщелоченного при выращивании кукурузы на зерно. Выявлена положительная динамика для следующих показателей: концентрация органического вещества, подвижного фосфора, общего и аммонийного азота.

Ключевые слова: органическое земледелие, отходы производства и потребления, компостирование, органоминеральный компост, экологические свойства почвы, чернозем выщелоченный, плодородие, кукуруза на зерно, концентрация питательных веществ.

среды, что приводит к снижению качества жизни населения. Одной из таких проблем является получение сельскохозяйственной продукции с использованием интенсивных технологий, где предусмотрено внесение высоких доз минеральных удобрений. В сложившейся ситуации является актуальным находить альтернативные способы получения высококачественной продукции при минимизации внесения искусственно созданных компонентов. 
Существует и другой важный аспект проблемы отходов. Наряду с лимитом ненарушенных площадей, обостряется проблема дефицита первичного сырья. Не стоит забывать, что практически все отходы имеют определенную ценность и потенциально могут быть использованы как вторичное сырье для производства качественно новой продукции (например, компостов, обогащенных питательными веществами). В состав таких компостов могут входить разнообразные отходы, начиная от органических или пищевых, заканчивая минеральными. Органические отходы (пищевые, коммунальные, животноводства или птицеводства) обладают высокой питательной ценностью и содержат многие элементы необходимые для развития растений. Кроме того, при внесении в почву они создают благоприятные условия для микробоценозов и почвенной мезофауны (Никифоренко, 2013). Минеральные отходы производств в значительной степени влияют на реакцию почвенной среды, обеспечивая растения важными микроэлементами.

Но, к сожалению, это все в теории, а в реалии очень малая доля отходов используется в компостировании. Значительная часть ценной органики в виде стерни, соломы, опада просто сжигается или отправляется на мусорные свалки. Отходы животноводства годами складируются около ферм, теряя ценный углерод. Некоторые отходы пищевой промышленности, содержащие ценные микроэлементы, также нередко «бездарно» сливаются или сбрасываются в мусор, а могли бы послужить добавками в кормлении животных.

Компостирование отходов и получение питательных удобрений ограничивается приусадебными участками, садами, частными огородами. На данный момент о производственных масштабах речь не идет. Хотя и существует масса исследований, доказывающих, что компосты благотворно влияют на плодородие нарушенных земель (Beluchenko, 2015; Khaliq, Abbasi, 2015; Okenmuo, 2018; Моностырский, 2019; Проценко и др., 2019). Органоминеральные смеси при грамотном подборе компонентов могут также успешно использоваться в детоксикации загрязненных ландшафтов, так как способны связывать поллютанты и переводить их в неподвижные соединения.

Использование органоминеральных компостов при выращивании сельхозпродукции - один из перспективных путей перехода на органическое земледелие. Актуальность этого вопроса на Кубани высока, поскольку спрос на качественное сырье увеличивается. Население все больше обращает внимание на качество потребляемой продукции. Расширение посевных площадей неизбежно, следовательно, при существующей системе земледелия, будет расти применение различ- ных удобрений и средств защиты растений, что приведет к снижению качественных показателей получаемого сырья. Частичная замена минеральных удобрений органическими позволит постепенно начать переход на экологическое земледелие и сохранить плодородие почв будущим поколениям. При этом важно давать объективную оценку качеству новых органоминеральных удобрений и их воздействию на свойства почвы, что является целью наших исследований в рамках гранта РФФИ и Администрации Краснодарского края (№ 19416-233003 р_мол_а).

Ранее, в рамках проводимых нами исследований, подобран благоприятный состав органоминерального компоста для внесения на черноземе выщелоченном слабогумусном. Изучение физико-химических характеристик компостов, отличающихся дозами полуперепревшего навоза КРС (ПН КРС) и фосфогипса показало, что их соотношение 7:1 является наиболее выгодным. В этом варианте компоста отмечены следующие особенности: замедление минерализация органического углерода, накопление аммонийного азота и фосфатов, оптимальная реакция $\mathrm{pH}$ среды. В результате биотестирования установлено, что сложные компосты не угнетают рост побегов кукурузы. Наиболее благоприятное воздействие и стимуляция роста растений отмечены в варианте сложный компост II (соотношение полуперепревшего навоза КРС и фосфогипса 7:1) (Антоненко и др., 2019; Антоненко и др., 2019; Антоненко и др., 2020). Результаты исследований, представленные в данной статье, дают оценку воздействия выбранного компоста на свойства исследуемой почвы.

\section{Метолика исслеАований}

Полевые испытания компоста II (ПН КРС + ФГ 7:1 + сено люцерны) осуществлялись на опытном участке кафедры ботаники и общей экологии Кубанского ГАУ в учебно-опытном хозяйстве (УОХ) «Кубань» г. Краснодара. Территория учхоза относится к Предкавказской лесостепной провинции (южная часть Прикубанской равнины). Роль исходных горных пород, при помощи которых образованы почвы хозяйства, выполняют лессовидные и аллювиальные отложения. Система орошения производится водами реки Кубань (КубаньГипрозем, 1991).

Почва на участке - чернозем выщелоченный слабогумусный сверхмощный легкоглинистый на лессовидных тяжелых суглинках. Исследуемая культура - кукуруза на зерно, гибрид среднеспелый «Краснодарский $377 \mathrm{AMB}$ ».

Схема полевого деляночного опыта включала 5 вариантов в трехкратной повторности. Площадь делян- 
Таблица 1. Агрохимический состав чернозема выщелоченного до закладки полевого поделяночного опыта, июль 2019 г.

\begin{tabular}{|l|l|l|}
\hline Показатель & $\begin{array}{l}\text { Единица } \\
\text { измерения }\end{array}$ & $\begin{array}{l}\text { Среднее } \\
\text { по опытному участку }\end{array}$ \\
\hline Содержание органического вещества & $\%$ & $3,5 \pm 0,2$ \\
\hline Общий азот по Кьельдалю & $\%$ & $0,24 \pm 0,01$ \\
\hline Запасы азота в верхнем слое почвы $(0-20$ см) & т/га & $6,0 \pm 0,3$ \\
\hline Концентрация подвижного фосфора $\left(\mathrm{P}_{2} \mathrm{O}_{5}\right)$ & мг/кг & $194,0 \pm 8,7$ \\
\hline Концентрация аммонийного азота & мг/кг & $7,5 \pm 0,6$ \\
\hline Концентрация нитратного азота & мг/кг & $11,5 \pm 0,7$ \\
\hline Реакция почвенной среды (рН водной вытяжки) & ед. $\mathrm{pH}$ & $7,2 \pm 0,4$ \\
\hline
\end{tabular}

ки - 30 м². Расположение повторений - сплошное, вариантов - рендомизированное.

Варианты полевого опыта:

1. Контроль - «чистая» почва без внесения удобрений.

2. Минеральные удобрения (МУ) - принятые для данной культуры нормы удобрений (аммофос).

3. Компост в дозе 20 т/га (ПН КРС + ФГ 7:1 + сено люцерны) без МУ.

4. Компост в дозе 40 т/га (ПН КРС + ФГ 7:1 + сено люцерны) без МУ.

5. Компост в дозе 60 т/га (ПН КРС + ФГ 7:1 + сено люцерны) без МУ.

Испытуемый сложный компост вносился осенью 2019 года под основную обработку. Весной 2020 г. был произведен посев кукурузы. Предшественник - озимая пшеница, уборка которой осуществлялась с измельчением соломы и распределением по поверхности почвы во всех вариантах опыта. В дальнейшем пожнивные остатки озимой пшеницы заделывались в почву дисковой бороной, а в сентябре проводилась основная обработка почвы - вспашка плугом на глубину $27-30 \mathrm{~cm}$.

Весной с целью уничтожения всходов сорной растительности, а также выравнивания поверхности почвы проводилась поверхностная обработка культиватором на глубину 8-10 см. Посев кукурузы проводили в оптимальные сроки, при прогревании почвы на глубине заделки семян до 12-14 ${ }^{\circledR}$ С. Норма высева - 70 тыс. шт./га. Посев проводился на глубину 6-8 см.

В течение вегетации кукурузы проводились 2 междурядные обработки:

1. в фазе 3-5 листьев культиваторами;

2. в фазе 6-8 листьев вручную при помощи тяпки.

В фазе полной спелости кукурузы, перед ее уборкой, проводили отбор почвенных образцов. Почву отбирали поделяночно с каждого варианта и повторности по диагонали через каждые 1,5 м. В образцах определяли: содержание органического вещества методом Тюрина в модификации ЦИНАО (ГОСТ 26213-91); общего азота по методу Кьельдаля; нитратного азота ионометрическим методом; обменного аммония по методу ЦИНАО (ГОСТ 26489-85); подвижного фосфора методом Чирикова в модификации ЦИНАО (ГОСТ 26204-91); рН 一 потенциометрическим методом.

Статистическая обработка результатов исследований проводилась в компьютерной программе Microsoft Office Excel.

\section{Результаты исслеАований}

Оценку агрономического состояния почвенного покрова на участке полевого опыта в учебном хозяйстве «Кубань» проводили до закладки опыта. Результаты показали, что содержание органического вещества составило 3,5\%, что является низким показателем (Вальков, 2008). К тому же, основные выращиваемые культуры в условиях данного района (пшеница, кукуруза, свекла, подсолнечник) хорошо реагируют на содержание гуматов в почве, и требовательны к содержанию органического вещества. При такой концентрации органики истощение почвы неизбежно, и без использования органических удобрений через 10-20 лет эти почвы будут непригодны для выращивания сельхозкультур (таблица 1).

Содержание общего азота в исследуемых образцах составило 0,24 $\pm 0,01 \%$, что говорит о среднем значении для данного типа почв. Запасы азота в верхнем слое почвы (0-20 см) находятся на уровне 6 т/га. На наш взгляд, перед посевом кукурузы такое количество азота является недостаточным для полноценного ее питания, поскольку данная культура требует повышенного содержания азота в почве. Концентрация подвижного фосфора в верхнем слое почвы находилась в среднем

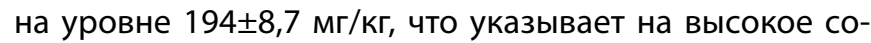


Таблица 2. Воздействие минеральных удобрений и органоминерального компоста на свойства чернозема выщелоченного на момент уборки кукурузы, сентябрь 2020 г.

\begin{tabular}{|l|l|l|l|l|l|}
\hline \multirow{2}{*}{ Вариант } & $\begin{array}{l}\text { Содержание } \\
\text { органического } \\
\text { вещества,\% }\end{array}$ & Общий азот,\% & $\mathbf{P}_{2} \mathbf{O}_{5}, \mathbf{м г / \mathbf { ~ }}$ & NH4+, мг/кг & Нитраты, мг/кг \\
\hline Контроль & $3,4 \pm 0,15$ & $0,24 \pm 0,01$ & $127,5 \pm 6,0$ & $5,2 \pm 0,3$ & $28,6 \pm 1,4$ \\
\hline $\begin{array}{l}\text { Минеральные } \\
\text { удбрения }\end{array}$ & $3,4 \pm 0,14$ & $0,26 \pm 0,01$ & $154,0 \pm 7,2$ & $10,0 \pm 0,6$ & $54,5 \pm 2,7$ \\
\hline Компост 20 т/га & $3,6 \pm 0,15$ & $0,25 \pm 0,01$ & $139,5 \pm 6,8$ & $6,8 \pm 0,3$ & $29,8 \pm 1,4$ \\
\hline Компост 40 т/га & $3,9 \pm 0,15$ & $0,26 \pm 0,01$ & $146,5 \pm 7,0$ & $7,5 \pm 0,4$ & $32,5 \pm 1,6$ \\
\hline Компост 60 т/га & $4,0 \pm 0,16$ & $0,27 \pm 0,01$ & $156,0 \pm 7,4$ & $8,6 \pm 0,4$ & $33,2 \pm 1,5$ \\
\hline
\end{tabular}

держание этого элемента в почве. Количество аммонийного азот в почве до внесения компостов составило

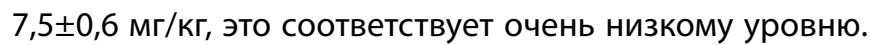
Аналогично низкая обеспеченность характерна и для

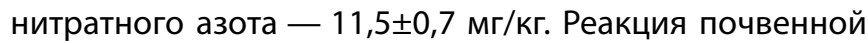
среды нейтральная, составила 7,2士0,4 ед. $\mathrm{pH}$ (таблица 1).

Таким образом, почва на участке полевого опыта характеризуется низким содержанием некоторых питательных элементов: органического вещества, аммонийного и нитратного азота. Низкие значения концентрации азота, вероятно, связаны с сезонной динамикой этого элемента, поскольку пробы отбирались в летний засушливый период после уборки озимой пшеницы, когда накопление нитратов и аммония минимальное. На наш взгляд, для восстановления экологических функций почвы и поддержания ее плодородия необходимо внесение органических форм удобрений.

К тому же, исследуемая в опыте культура (кукуруза) высокотребовательна и отзывчива к внесению органических и минеральных удобрений. Она усваивает питательные вещества вплоть до созревания зерна, вынося из почвы значительное их количество. Причем большая часть всех питательных элементов потребляется из почвы во вторую половину вегетационного периода. Так, на создание 1 т зерна требуется 24-30 кг азота, 10-12 кг фосфора, 25-30 кг калия (Краснодар, 2016).

При любом уровне применения минеральных удобрений важный резерв восполнения питательных веществ в почве - это органическое удобрение. Рекомендуется вносить 40-60 т/га навоза с последующим запахиванием, поскольку в открытом виде навоз теряет до 50\% полезных свойств в течение одного дня. Органические удобрения способствуют не только повышению концентрации питательных веществ за счет минерализации органического вещества, но и заметному улучшению физических свойств почвы (снижению плотности, улучшению аэрации и структурного сложения). Физические свойства почвы являются частью системы, и играют немаловажную роль в трансфор- мации химических элементов почвы и формировании благоприятных условий обитания живых организмов. Поэтому мы рассматриваем переход на органическое земледелие и применение органоминеральных компостов как комплексное действие, которое изменяет основные свойства почвы в лучшую сторону (Антоненко и др., 2017; Мельник, 2018).

Проведенные исследования по оценке воздействия компоста на агрохимические свойства чернозема выщелоченного показали, что внесение органоминерального удобрения повышает содержание органического вещества в среднем на 5,9-17,6\% по сравнению с контролем и вариантом с применением минеральных удобрений. Максимальные значения характерны для варианта с компостом в дозах 40 и 60 т/га. Концентрация общего азота была минимальной на контроле $(0,24 \pm 0,01 \%)$, что логично, поскольку в этом варианте не использовали никаких удобрений. Осеннее внесение минерального удобрения (аммофоса) способствовало повышению доли азота

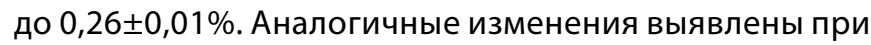
использовании органоминерального компоста. При этом уровень содержания общего азота при внесении аммофоса и компоста в дозе 40-60 т/га одинаковый. То есть компост по обеспечению почвы азотом можно сравнить с вносимыми минеральными удобрениями (таблица 2).

Минимальные значения подвижного фосфора отмечены в контрольном варианте $(127,5 \pm 6,0$ мг/кг). Применение минерального удобрения и компоста в дозе 60 т/ га равнозначно увеличивало концентрацию данного питательного элемента. Это указывает на возможность замены некоторых минеральных удобрений органическими, поскольку часто их эффективность находится на одном уровне. При этом неблагоприятное действие органики в разы меньше по сравнению с минеральными удобрениями, не говоря уже о их стоимости. При использовании компоста в дозах 20 и 40 т/га также отмечается повышение доли фосфора по сравнению с контролем на 9,4 и 14,9\% (таблица 2). 


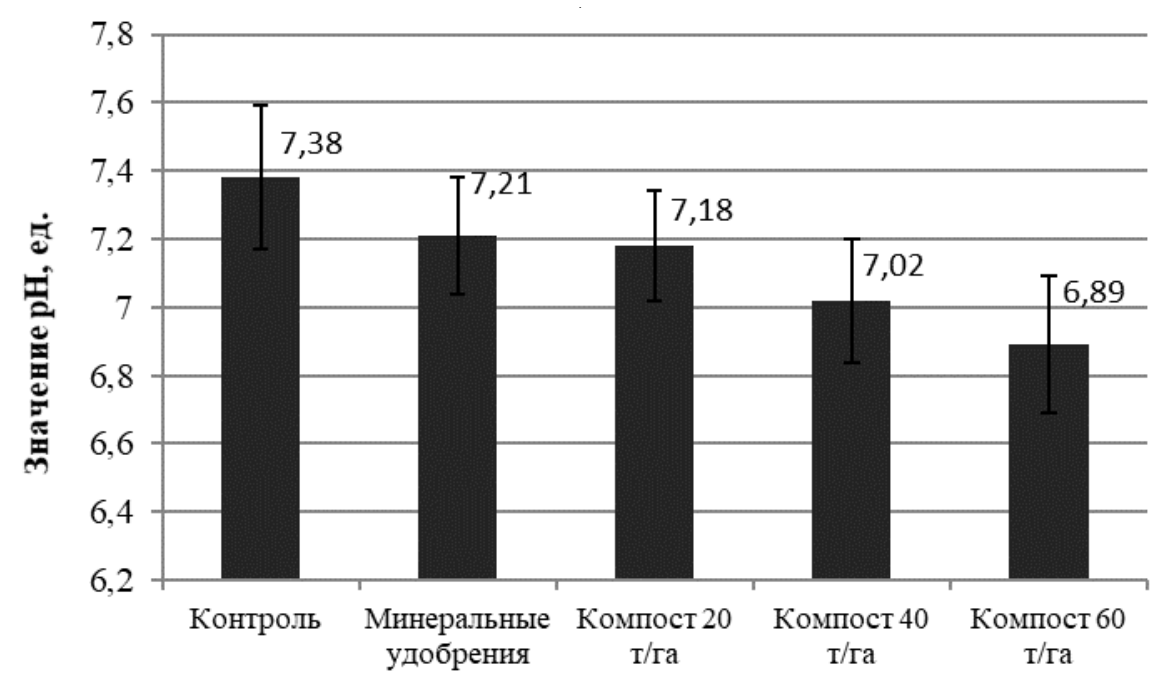

Рис. 1. Реакция среды чернозема выщелоченного при внесении минеральных удобрений и компостов, ед. $\mathrm{pH}$ (сентябрь, 2020 г.)

По обеспеченности аммонийным азотам почва на всех делянках опыта характеризовалась очень низким уровнем. Это связано с тем, что отбор проб проводился в конце вегетационного периода кукурузы и большую часть аммонийного азота поглотили растения. Максимальная концентрация аммонийного азота была в почве, где вносились только минеральные

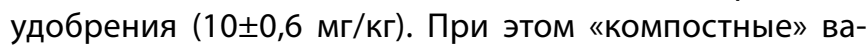
рианты несколько проигрывали минеральным удобрениям, но заметно увеличили долю аммонийного азота по сравнению с контролем. Концентрация данного питательного элемента повысилась по сравнению с контролем на 30,8, 44,2 и 65,4\% соответственно, в вариантах 20, 40 и 60 т/га компоста (таблица 2).

Содержание нитратного азота было на высоком уровне во всех вариантах почвы и заметно увеличилось по сравнению контрольной почвой до внесения удобрений. На наш взгляд, это связано с сезоном отбора проб. Именно в осеннее, более увлажненное время, происходит мобилизация нитратного азота. Если сравнивать концентрацию этого элемента по вариантам опыта, то максимум отмечен в почве, где вносили минеральные удобрения (54,5 22,7 мг/кг). Тогда как при использовании компоста в дозах 20-60 т/га заметных отличий по сравнению с контролем выявлено не было (таблица 2).

Полевые испытания показали, что применение сложного компоста способствовало изменению реакции почвенной среды от слабощелочной $(7,4 \pm 0,21$

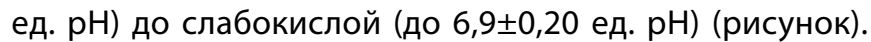
Органоминеральный компост в дозах 40 и 60 т/га способствовал незначительному подкислению среды. Ве- роятно, за счет этого поступление нитратного азота в растения кукурузы было более эффективным, и его концентрация в почве в конце вегетационного периода по сравнению с вариантом «минеральные удобрения» была ниже, поскольку именно в подкисленной среде поглощение корнями нитратов из почвы идет интенсивнее. Снижение $\mathrm{pH}$ за счет внесения компоста связано с его составом, а именно с содержание фосфогипса. Реакция среды этого отхода кислая и составляет около 4,5-5,0 ед. $\mathrm{pH}$.

В заключении отметим, что наиболее благоприятными дозами внесения органоминерального компоста, при которых отмечены статистически значимые различия по сравнению с контролем, являются 40 и 60 т/га. При этом высокие показатели по обеспеченности почвы питательными элементами характерны для вариантов с применением только минеральных удобрений и органоминерального компоста в дозе 60 т/га. Эти два варианта отличались максимальными значениями концентрации азотных соединений и фосфора. Так их можно считать равнозначными, то есть внесение принятой нормы минеральных удобрений и сложного компоста в дозе 60 т/га равноценно. При переходе на органическое земледелие стоит учитывать этот факт и рассматривать возможность полного или частичного отказа от дорогостоящих минеральных удобрений. К тому же, не стоит забывать, что минеральные удобрения не восполняют утраченную почвой органику. Данный факт хорошо прослеживается в результатах наших исследований. Только органические и органоминеральные удобрения способны поддерживать почвенное плодородие, которое и является «депо» для всех питательных веществ. 


\section{ЛИТЕРАТУРА}

1. Антоненко Д.А., Мельник 0.А., Никифоренко Ю.Ю. Влияние органо-минеральных удобрений на свойства чернозема выщелоченного и состав почвенной мезофауны / Д.А. Антоненко, 0.А. Мельник, Ю.Ю. Никифоренко // Труды Кубанского государственного аграрного университете.— Краснодар, 2017. — № 64.—C. 43-51.

2. Антоненко Д.А., Мельник 0.А., Никифоренко Ю.Ю. Использование сложных компостов на основе отходов в системе органического земледелия / Д.А. Антоненко, 0.А. Мельник, Ю.Ю. Никифоренко // Современная наука: актуальные проблемы теории и практики. Серия «Естественные и технические науки» — 2019. — № 11. — C 7-11.

3. Антоненко Д.А., Мельник О.А., Никифоренко Ю.Ю. Особенности формирования сложного компоста на основе полуперепревшего навоза КРС и фосфогипса / Д.А. Антоненко, 0.А. Мельник, Ю.Ю. Никифоренко // Экологический вестник Северного Кавказа — Краснодар, 2019.— Т. 15.— № 4.— (37-42.

4. Антоненко Д.А., Мельник 0.А., Никифоренко Ю.Ю. Оценка токсичности сложных компостов методом биотестирования // Современная наука: актуальные проблемы теории и практики. Серия «Естественные и технические науки» - 2020. — № 8-2. — C 5-9.

5. Мельник 0.А. Сложный компост как источник органического вещества в почве агроландшафтов / 0.А. Мельник // Экологические проблемы развития агроландшафтов и способы повышения их продуктивности: сб. матер. Междунар. науч. экол. конф. — Краснодар: КубГАУ, 2018. — С. 287-292.

6. Монастырский 0.А. Органическое земледелие и получение экологичных пищевых продуктов в России / О.А. Монастырский, Е.В. Кузнецова, Л.П. Есипенко // Агрохимия. - Москва, 2019. - № 1.- С. 3-4.

7. Никифоренко Ю.Ю. Состав почвенной мезофауны в черноземе обыкновенном при внесении сложного компоста / Ю.Ю. Никифоренко // Экологический вестник Северного Кавказа - Краснодар, 2013. - Т. 9. - № 2. - С 30-39.

8. Проценко Е.П. Экологические аспекты применения органических компостов из отходов на черноземных почвах / Е.П. Проценко, Н.И. Косолапова, С.Г. Сапронова, Е.Ю. Алферова, Н.П. Неведров // Отходы, причины их образования и перспективы использования: сб. матер. Междунар. науч. экол. конф.- Краснодар: КубГАУ, 2019.—- С. 599-601.

9. Технический отчет о почвенном обследовании опытного поля КубГАУ г. Краснодара Краснодарского края. — Краснодар: КубаньГипрозем, 1991. — 22 с.

10. Технология возделывания кукурузы. Рекомендации / сост. И.А. Лобач [и др.]. — Краснодар: изд-во КНИИСХ им. П.П. Лукьяненко, 2016. — 41 с.

11. Belyuchenko I.S. Living organisms in household and production wastes as functional basis of compound compost formation / I.S. Belyuchenko // Ecology, Environment and Conservation Paper. — Suppl. Issue. - 2015. - Vol. 21. - P. 47-56.

12. Khaliq A. Improvement in the physical and chemical characteristics of degraded soils supplemented with organic-inorganic amendments in the Himalayan region of Kashmir, Pakistan / A. Khaliq, M.K. Abbasi // Catena. - 2015. - Vol. 126. - P. 209-219

13. Luo Y., Liang J., Zeng G., Chen M., Mo D., Li G., Zhang D. Seed germination for toxicity evaluation compost: its Roles, Problems and Prospects // Waste Management. - 2018. - T. 71.-C. 109-114.

14. Okenmuo F.C. Short-term amelioration of soil properties and maize yield enhancement using animal wastes in degraded hydromorphic soils of Southeastern Nigeria / F.C. Okenmuo, 0.U. Odii, C.C. Okolo // Journal of Soil Science and Environmental Management. — 2018. — Vol. 9(6). — P. 91-97.

( Антоненко Дарья Алексеевна ( dasha-slav@rambler.ru ), Никифоренко Юлия Юрьевна ( petuh_yulya@mail.ru ),

Мельник Ольга Александровна ( melnik_olga240781@mail.ru ).

Журнал «Современная наука: актуальные проблемы теории и практики» 